\title{
A aptidão de uso da terra como base para o planejamento da utilização dos recursos naturais no município de São João do Polêsine - RS
}

\author{
Land suitability as a base for natural resource use planning at the São João do Polesine \\ county - Rio Grande do Sul/State - Brazil \\ Fabrício de Araújo Pedron ${ }^{1}$ Everton Luís Poelking ${ }^{2}$ Ricardo Simão Diniz Dalmolin ${ }^{3}$ \\ Antonio Carlos de Azevedo ${ }^{3}$ Egon Klamt ${ }^{4}$
}

\section{RESUMO}

A falta de conhecimento da aptidão de uso da terra e do planejamento adequado da sua utilização tem sido fato freqüente ocasionando impactos negativos ao meio ambiente. Neste sentido, os objetivos deste trabalho foram determinar a aptidão de uso, uso atual e os conflitos de uso da terra, visando contribuir para o planejamento racional dos recursos naturais no município de São João do Polêsine (SJP), RS. A análise ambiental foi efetuada através da integração de diferentes planos de informações como solos, relevo, hidrografia, aptidão agrícola, uso das terras e áreas de preservação permanente (APP). SJP apresenta mais de $50 \%$ de sua área destinada a atividades agropecuárias, 14,8\% do município enquadra-se como APP, sendo a metade dessa área utilizada inadequadamente. Os principais problemas relacionam-se com a utilização inadequada dos seus recursos naturais, sem considerar a legislação ambiental e a aptidão das terras no processo de planejamento.

Palavras - chave: levantamento de solos, aptidão agrícola, conflitos de uso das terras, sensoriamento remoto, $S I G$

\section{ABSTRACT}

The lack of knowledge on land use suitability and appropriate planning of its use have been a frequent reality causing negative impacts on the environment. In this way, the objective of this research was to determine land suitability, current land use and conflicts of use, seeking to contribute for the rational planning of the natural resources in the São João do Polêsine (SJP), RS. The environmental analysis was made through the integration of different plans of information as soils, relief, hydrography, agricultural suitability, land use and areas of permanent preservation (APP). SJP presents more than $50 \%$ of its area destined to agricultural activities, $14.8 \%$ of the SJP are framed as APP, with half of that area being used inadequately. The main problems of the county are related to the inadequate use of natural resources, without considering information regarding to the environmental legislation and land suitability, in the planning process.

Key words: soil survey, land suitability, land use conflicts, remote sensing, GIS

\section{INTRODUÇÃO}

A falta de um planejamento racional de uso da terra, seja pela falta de conhecimento, seja pela necessidade dos agricultores, tem promovido diversos impactos negativos, muitas vezes chegando a limites críticos em determinadas regiões, resultando em degradação ambiental e redução da qualidade de vida, não só para a comunidade rural, mas também para toda população (DENT \& YOUNG, 1993).

A recuperação, conservação e exploração sustentável dos recursos naturais exigem conhecimento das suas propriedades e da situação em relação aos efeitos das atividades antrópicas. Nesse sentido, o diagnóstico do recurso solo, juntamente com outros elementos ambientais, é uma excelente ferramenta na determinação de problemas, como os conflitos de uso

\footnotetext{
${ }^{1}$ Departamento de Solos, Universidade Federal de Santa Maria (UFSM), Programa de Pós-graduação em Ciência do Solo (PPGCS) da UFSM, Santa Maria, RS, Brasil.

${ }^{2}$ PPGCS, UFSM, Santa Maria, RS, Brasil. E- mail: evertonpoelking@ hotmail.com.

${ }^{3}$ Departamento de Solos da UFSM, CCR, 97105-900, Santa Maria, RS, Brasil. E- mail: dalmolin@ccr.ufsm.br. Autor para correspondência

${ }^{4}$ Departamento de Solos da Universidade Federal do Rio Grande do Sul (UFRGS), Porto Alegre, RS, Brasil.
} 
das terras, os quais podem auxiliar no planejamento racional de todo o ambiente em questão (FORMAGGIO et al., 1992; DENT \& YOUNG, 1993; RODRIGUES et al., 2001). Terra não significa somente o solo como base de sustentação do ambiente, mas também todos os demais elementos e fatores ambientais que influenciam na manutenção do ecossistema (LEPSCH et al., 1991; RAMALHO FILHO \& BEEK, 1995).

São João do Polêsine tem sua economia baseada no setor primário, com predomínio de minifúndios utilizando mão-de-obra familiar (KLAMT et al., 1997). As características intrínsecas da agricultura familiar, aliadas às poucas alternativas de exploração agrícola no município, devido principalmente à sua geomorfologia, têm provocado situações de degradação ambiental pela forte pressão antrópica sobre áreas que oferecem algum tipo de risco devido à sua ocupação. Dessa forma, este trabalho procurou determinar e analisar as áreas de conflitos de uso das terras, através da geração e cruzamento de mapas temáticos (planos de informação) como solos, relevo, sistema de drenagem e cobertura vegetal, visando contribuir para a adequação de uso e planejamento racional dos recursos naturais em nível municipal.

\section{MATERIAL E MÉTODOS}

A área de estudo, com aproximadamente $89 \mathrm{~km}^{2}$, está localizada na região central do Rio Grande do Sul, na transição entre a região do Planalto e da Depressão Central, cujas coordenadas geográficas são: $29^{\circ} 35^{\prime} 08^{\prime \prime}$ a $29^{\circ} 41^{\prime} 50^{\prime \prime}$ de latitude sul e de $53^{\circ} 32^{\prime} 08^{\prime \prime}$ a $53^{\circ} 22^{\prime} 56^{\prime \prime}$ de longitude oeste. O município de SJP apresenta clima do tipo Cfa, segundo a classificação de Köppen. A temperatura média das mínimas anual é em torno de $14^{\circ} \mathrm{C}$ e média das máximas anual de $25^{\circ} \mathrm{C}$. A precipitação média anual é de $1700 \mathrm{~mm}$ (BURIOL et al., 1979). A principal atividade econômica é a agricultura, destacando-se a produção de arroz irrigado, milho, feijão e fumo.

A análise ambiental e o diagnóstico do uso das terras foram efetuados através da produção e sobreposição de diferentes planos de informação - PI, conforme a figura 1, gerando informações sobre a adequação de uso das terras. Inicialmente, foi determinado o mapa de aptidão agrícola das terras utilizando-se as informações contidas no levantamento semidetalhado dos solos do município (KLAMT et al.,
1997). O mapa de solos foi digitalizado e sua legenda (Tabela 1) atualizada conforme o Sistema Brasileiro de Classificação de Solos (EMBRAPA, 1999). O mapa de aptidão de uso agrícola das terras foi gerado de acordo com RAMALHO FILHO \& BEEK (1995).

O mapa de uso atual das terras foi gerado a partir da classificação supervisionada de imagem do sensor ETM+ (Landsat 7), bandas 3, 4 e 5, do ano de 2002, utilizando-se o classificador estatístico "MAXVER" (máxima verossimilhança), integrante do aplicativo Spring - Sistema de Processamento de Informações Georeferenciadas (CAMARA et al., 1996), versão 4.0, desenvolvido pelo INPE - Instituto Nacional de Pesquisas Espaciais. Foram estabelecidas cinco classes de uso: floresta (nativa e plantada), agricultura (culturas anuais), campo (pastagens naturais e vegetação secundária), água (rios, córregos e lagos) e outros (solo exposto, rodovias e área urbana). Pequenos erros de classificação foram corrigidos pela reambulação temática.

As cartas hipsométrica e de declividades foram obtidas a partir da digitalização da carta topográfica (planialtimétrica) da Diretoria do Serviço Geográfico do Exército, Folhas de Camobi e Faxinal do Soturno, com distância vertical de 20 metros e escala 1:50.000. A carta de declividade do terreno foi dividida nas classes de $0-3 \%, 3-8 \%, 8-13 \%, 13-20 \%, 20-$ $45 \%, 45-100 \%$ e acima de $100 \%$. A carta hipsométrica foi dividida em classes de 20 metros variando da menor altitude até a maior altitude encontrada na área de trabalho.

O mapa de áreas de preservação permanente (APP) foi construído com base na Resolução n. 303 (CONAMA, 2002), e na Lei Federal n. 4.771 (BRASIL, 1965). Foram classificadas áreas com declividade acima de $45^{\circ}$ e topos de morros através da carta hipsométrica e de declividades, matas ciliares de rios e arroios e nascentes através da vetorização do sistema de drenagem e fontes d'água existentes na carta topográfica e na imagem ETM+, conforme as legislações citadas.

O mapa de conflitos de uso das terras foi gerado a partir dos cruzamentos dos mapas de aptidão agrícola das terras, uso atual das terras e áreas de preservação permanente. Nestes cruzamentos, nos casos de unidades de mapeamento compostas, nas quais ocorrem diferentes classes de aptidões das terras, foram consideradas aquelas de maior restrição ao uso 


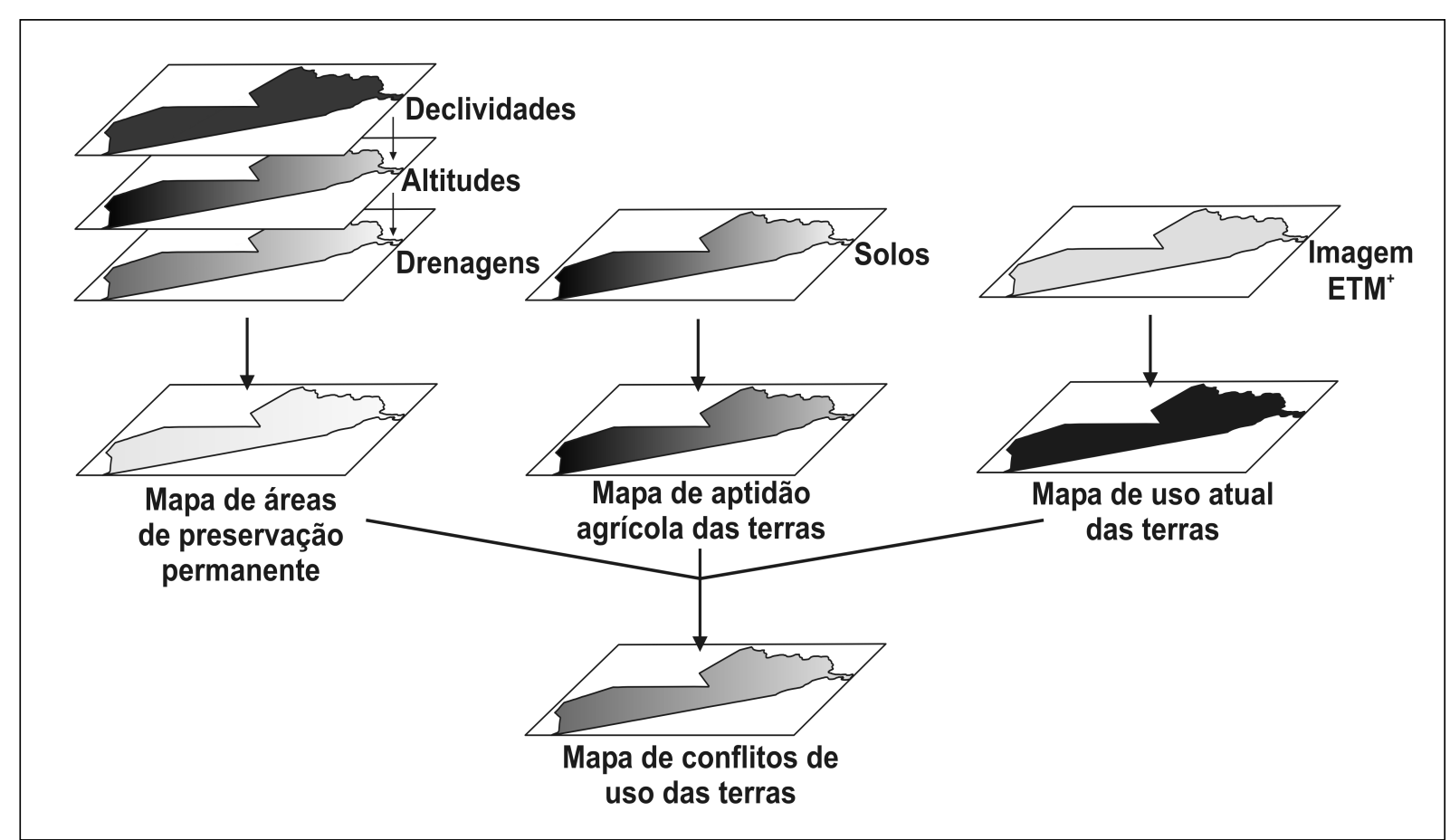

Figura 1 - Organograma do método de construção e cruzamento dos diferentes planos de informações utilizados no trabalho. (município de São João do Polêsine, RS).

agrícola. Todas as etapas de cruzamento dos PI foram efetuadas pelo aplicativo Spring.

\section{RESULTADOS E DISCUSSÃO}

Tendo em vista a aptidão agrícola das terras (Tabela 2), a qual pode ser visualizada no mapa da Figura 2A, SJP apresenta pelo menos $70 \%$ de sua área com alguma aptidão para lavouras anuais em um dos três níveis de manejo (A,B e C), considerando as associações que apresentam em média o mesmo percentual de área para cada classe de solo que as integram. Também considerando as associações, pelo menos $30 \%$ da área não possui aptidão para lavouras anuais, devendo ser destinados a pastagens, silvicultura e preservação natural.

Os dados referentes ao uso atual das terras mostram que a maior área é utilizada com agricultura anual $(37,4 \%)$ e pastagens naturais $(24,2 \%)$, totalizando mais de $50 \%$ do município destinado a atividades agropecuárias. A conformação do uso das terras é apresentado na Figura 2B, na qual se pode observar que grande parte das áreas de agricultura são localizadas na várzea do rio Soturno, ao norte do município, onde predomina a cultura do arroz irrigado. Também fica evidente a presença de floresta nativa $(29,0 \%)$ em áreas de restrito acesso para produção agrícola e pecuária, como topo de morros e áreas com maior declividade. As áreas de campo, geralmente, ocorrem em faixas de transição entre as menores declividades, usadas como lavoura e as maiores, como floresta. A utilização de imagem orbital na determinação do uso das terras mostrou-se eficiente em termos de agilidade e confiabilidade devido às especificidades da classificação digital associadas à reambulação temática, tal como já mencionado por FORMAGGIO et al. (1992) e PIROLI et al. (2002).

O levantamento das áreas de preservação permanente (Figura 3B) aponta que 14,8\% do município de SJP enquadram-se como APP por apresentarem declividade acima de $100 \%$, ocorrerem em topos de morros ou próximos a nascentes, rios e arroios. Verificase que há uma sub-estimativa das APP, visto que é impossível identificar e localizar todas as nascentes, vertentes e olhos d'água distribuídos nas mais diversas feições geomorfológicas existentes na área de estudo. No entanto, as áreas de maior expressividade puderam ser extraídas das cartas topográficas e imagens orbitais, 
Tabela 1 - Classes de solos e associações de solos existentes em São João do Polêsine, segundo KLAMT et al. (1997), atualizadas por DALMOLIN et al. (2004).

\begin{tabular}{|c|c|c|c|}
\hline Solos & Símbolo & Aptidão $^{(1)}$ & Área (ha) \\
\hline $\begin{array}{l}\text { Planossolo Hidromórfico distrófico - eutrófico arênico, A proeminente - } \\
\text { moderado, textura argilosa, relevo suave ondulado }\end{array}$ & SGde & $2(a) b c$ & 1.285 \\
\hline $\begin{array}{l}\text { Alissolo Hipocrômico argilúvico típico, textura média, relevo suavemente } \\
\text { ondulado }\end{array}$ & APt & $2(a) b c$ & 25 \\
\hline $\begin{array}{l}\text { Alissolo Crômico argilúvico abrúptico, A moderado, textura argilosa, } \\
\text { relevo suave ondulado }\end{array}$ & ACt 1 & $2(a) b c$ & 537 \\
\hline $\begin{array}{l}\text { Alissolo Crômico argilúvico abrúptico, A moderado, textura argilosa, } \\
\text { relevo ondulado - forte ondulado }\end{array}$ & ACt 2 & $2(a) b c / 4 p$ & 311 \\
\hline $\begin{array}{l}\text { Neossolo Litólico eutrófico típico, A moderado, textura média, relevo } \\
\text { montanhoso }\end{array}$ & RLe & $5 \mathrm{NS}$ & 864 \\
\hline $\begin{array}{l}\text { Neossolo Litólico distrófico típico, A proeminente, textura média, relevo } \\
\text { ondulado, substrato arenito e siltito }\end{array}$ & RLd & $4 \mathrm{p}$ & 31 \\
\hline $\begin{array}{l}\text { Argissolo Vermelho - Amarelo alumínico alissólico, A moderado, textura } \\
\text { argilosa, relevo suave ondulado }\end{array}$ & PVAa & $2(a) b c$ & 123 \\
\hline $\begin{array}{l}\text { Gleissolo Háplico Ta alumínico típico, A moderado, textura média, relevo } \\
\text { plano }\end{array}$ & GXva & $2(\mathrm{~b}) \mathrm{c}$ & 1.385 \\
\hline Chernossolo Argilúvico órtico típico, textura média, relevo forte ondulado & MTo & $2 \mathrm{a}(\mathrm{b})$ & 14 \\
\hline $\begin{array}{l}\text { Cambissolo Háplico Ta eutrófico típico, A chernozêmico, textura argilosa, } \\
\text { relevo forte ondulado, substrato basalto }\end{array}$ & CXve & $3(\mathrm{a}) / 4 \mathrm{p}$ & 4 \\
\hline Associação ACt 2 - CXve - RLe & A 1 & $2(\mathrm{a}) \mathrm{bc} / 3(\mathrm{a}) / 4 \mathrm{p} / 5 \mathrm{NS}$ & 1.670 \\
\hline Associação PVAa - ACt 2 - CXve & A 2 & $2(a) b c / 3(a) / 4 p$ & 1.500 \\
\hline Associação PVAa - ACt 1 & A 3 & $2(\mathrm{a}) \mathrm{bc}$ & 166 \\
\hline Associação APt - RLe & A 4 & 2(a)bc/5NS & 138 \\
\hline Associação ACt $2-\mathrm{APt}$ & A 5 & $2(a) b c / 4 p$ & 581 \\
\hline Associação ACt 2 - RLd & A 6 & $2(a) b c / 4 p$ & 167 \\
\hline Associação CXve - RLe & A 7 & $3(\mathrm{a}) / 4 \mathrm{p} / 5 \mathrm{NS}$ & 89 \\
\hline Associação APt - SGed & A 8 & $2(a) b c$ & 20 \\
\hline Associação Cambissolo e solos aluviais não caracterizados & A 9 & 6 & 61 \\
\hline
\end{tabular}

(1) Aptidão agrícola das terras (Ramalho Filho \& Beek, 1995): 2 - aptidão regular para lavouras; 3 - aptidão restrita para lavouras; 4 aptidão para pastagem plantada; 5 - aptidão para silvicultura e/ou pastagem natural; 6 - terras sem aptidão agrícola, destinadas à preservação natural; (a) - classe restrita de aptidão ao nível de manejo A; a - classe regular de aptidão ao nível de manejo A; b - classe regular ao nível de manejo B; (b) - classe restrita ao nível de manejo B; c - classe regular ao nível de manejo C; p - classe regular para pastagens plantadas ao nível de manejo B; $\mathrm{N}$ - classse boa para pastagem natural ao nível de manejo A; $\mathrm{S}$ - classe boa para silvicultura ao nível de manejo B.

sendo apresentadas na tabela 2, destacando-se os topos de morros com $9,6 \%$ da área total e as matas ciliares $\operatorname{com} 4,8 \%$.

Os principais conflitos de uso das terras no município de SJP estão relacionados com as áreas de declividade acentuada, áreas ciliares e uso agrícola de solos sem aptidão adequada (Figura 3A). Em parte das áreas de morros, a floresta foi destruída dando lugar à agricultura e à pecuária, enquanto áreas de vegetação ciliar, principalmente junto ao rio Soturno, também foram parcialmente destruídas e convertidas em áreas de produção orizícola. Partes dessas áreas são consideradas APP's e, no entanto, estão sendo utilizadas no processo produtivo, muitas delas de maneira inadequada, provocando depauperamento da qualidade ambiental. PIROLI et al. (2002), trabalhando em área próxima, com geomorfologia e cultura semelhante, também verificaram o mesmo padrão de uso da terra.

O cruzamento dos PI's aptidão agrícola e uso atual das terras resultaram em conflitos de uso para $27,9 \%$ das terras. Isso significa que existem 2.509 hectares sendo utilizados de maneira inadequada, enquanto $18,8 \%$ encontram-se sub-utilizados, ou seja, 1.683 hectares possuem aptidão para uso mais intenso que o atual. A principal causa dos conflitos de uso é a presença de lavouras e pastagens em áreas com aptidão apenas para silvicultura e preservação natural. Tal fato

Ciência Rural, v.36, n.1, jan-fev, 2006. 
Tabela 2 - Áreas dos PI's de aptidão agrícola das terras, uso atual das terras e das áreas de preservação permanente, e resultado dos cruzamentos entre esses planos de informações para o município de São João do Polêsine.

\begin{tabular}{|c|c|c|}
\hline \multirow{2}{*}{ Planos de informações } & \multicolumn{2}{|c|}{ Área* } \\
\hline & ha & $\%$ \\
\hline \multicolumn{3}{|l|}{ Aptidão agrícola das terras } \\
\hline $2(a) b c$ & 2.322 & 25,9 \\
\hline $2(\mathrm{~b}) \mathrm{c}$ & 1.385 & 15,4 \\
\hline $2(a) b c / 4 p$ & 893 & 10,0 \\
\hline $2 \mathrm{a}(\mathrm{b})$ & 14 & 0,2 \\
\hline $3(a) / 4 p$ & 4 & 0,04 \\
\hline $4 \mathrm{p}$ & 31 & 0,3 \\
\hline $5 \mathrm{NS}$ & 864 & 9,6 \\
\hline 6 & 61 & 0,7 \\
\hline $2(a) b c / 3(a) / 4 p$ & 1.500 & 16,7 \\
\hline $2(a) b c / 3(a) / 4 p / 5 N S$ & 1.670 & 18,6 \\
\hline 2(a)bc/5NS & 138 & 1,5 \\
\hline $3(a) / 4 p / 5 N S$ & 89 & 1,0 \\
\hline \multicolumn{3}{|l|}{ Uso atual das terras } \\
\hline Agricultura anual & 3.356 & 37,4 \\
\hline Floresta & 2.631 & 29,3 \\
\hline Corpos d'água & 158 & 1,8 \\
\hline Campo natural & 2.175 & 24,2 \\
\hline $\begin{array}{l}\text { Outros } \\
\text { Áreas de preservação permanentes (APP) }\end{array}$ & 651 & 7,3 \\
\hline Matas ciliares & 429 & 4,8 \\
\hline Nascentes e fontes naturais & 24 & 0,3 \\
\hline Topos de morros & 860 & 9,6 \\
\hline Áreas com declividade > $100 \%$ & 11 & 0,1 \\
\hline $\begin{array}{l}\text { Áreas não enquadradas como APP } \\
\text { Aptidão agrícola x uso atual das terras }\end{array}$ & 7647 & 85,2 \\
\hline Uso adequado das terras & 4.621 & 51,5 \\
\hline Sub-utilização das terras & 1.683 & 18,8 \\
\hline Uso inadequado das terras (super-utilização) & 2.509 & 27,9 \\
\hline Corpos d'água & 158 & 1,8 \\
\hline Aptidão agrícola x APP’s & & \\
\hline Uso adequado das terras segundo aptidão & 122 & 1,4 \\
\hline Uso inadequado das terras segundo aptidão & 1.202 & 13,4 \\
\hline $\begin{array}{l}\text { Áreas não enquadradas como APP } \\
\text { Uso atual das terras x APP's }\end{array}$ & 7.647 & 85,2 \\
\hline Agricultura anual & 441 & 4,9 \\
\hline Floresta & 541 & 6,0 \\
\hline Corpos d'água & 16 & 0,2 \\
\hline Campo natural & 248 & 2,8 \\
\hline Outros & 78 & 0,9 \\
\hline Áreas não enquadradas como APP & 7.647 & 85,2 \\
\hline
\end{tabular}

* A soma das porcentagens pode não igualar a 100 devido a erros de arredondamentos.

ocorre devido à fragilidade desses ambientes relacionados à declividade, pedregosidade, rochosidade, provocando restrições ao uso de mecanização, assim como a ocorrência de solos com pouca profundidade efetiva, sendo mais suscetíveis a erosão, estresse hídrico e oferecendo maiores restrições ao desenvolvimento radicular das culturas anuais, como é o exemplo de alguns Neossolos, Chernossolos e Cambissolos (STRECK et al., 2002; AZEVEDO \& DALMOLIN, 2004; DALMOLIN et al., 2004), os quais são incorporados ao processo produtivo, principalmente pela agricultura familiar, devido à falta de opções e necessidade de sustento das famílias.

Analisando as informações resultantes do cruzamento do mapa de aptidão agrícola das terras e o mapa de APP, é possível observar que, em 13,4\% da área, ocorrem conflitos entre a aptidão agrícola e a legislação que define as APP. Esse problema é resultado da extensão de áreas com aptidão agrícola para lavouras e pastagens plantadas e naturais sobre APP. Os conflitos entre a aptidão agrícola das terras e as APP são decorrentes do fato que o sistema proposto por RAMALHO FILHO \& BEEK (1995) não inclui a legislação na determinação das classes de aptidão. Nesse caso, as informações do mapa de aptidão agrícola devem ser cruzadas com as do mapa de APP antes de serem utilizadas no planejamento de uma região. Da mesma forma, em qualquer planejamento, é imprescindível a utilização de material cartográfico adequado, principalmente no que se refere à escala dos mapas, para que as informações obtidas sejam compatíveis com a realidade e com o tipo de análise realizado. DALMOLIN et al. (2004) alertam que a utilização de mapas de solos com escala pequena não são compatíveis com estudos de áreas municipais, devendo, neste caso, serem utilizados levantamentos de solos semidetalhados e detalhados com escala de publicação maior que 1:60.000.

As informações do cruzamento entre o mapa de APP e o mapa de uso atual das terras mostram que, dos $14,8 \%$ da área total que pertencem as APP, 6,0\% estão sendo utilizados com floresta nativa, fato este positivo ao meio ambiente. No entanto, $8,6 \%$ dessa área, ou seja, 58\% do total das APP estão sendo utilizadas inadequadamente sob a forma de lavouras e pastagens. A transformação de áreas com vegetação natural em lavouras e outros usos antrópicos ocasiona desequilíbrio ambiental, afetando entre tantos a qualidade da água devido aos diversos insumos utilizados na agricultura (RHEINHEIMER et al., 2003). A extensa área orizícola de SJP é alvo dos impactos causados pelo manejo inadequado da água de irrigação 


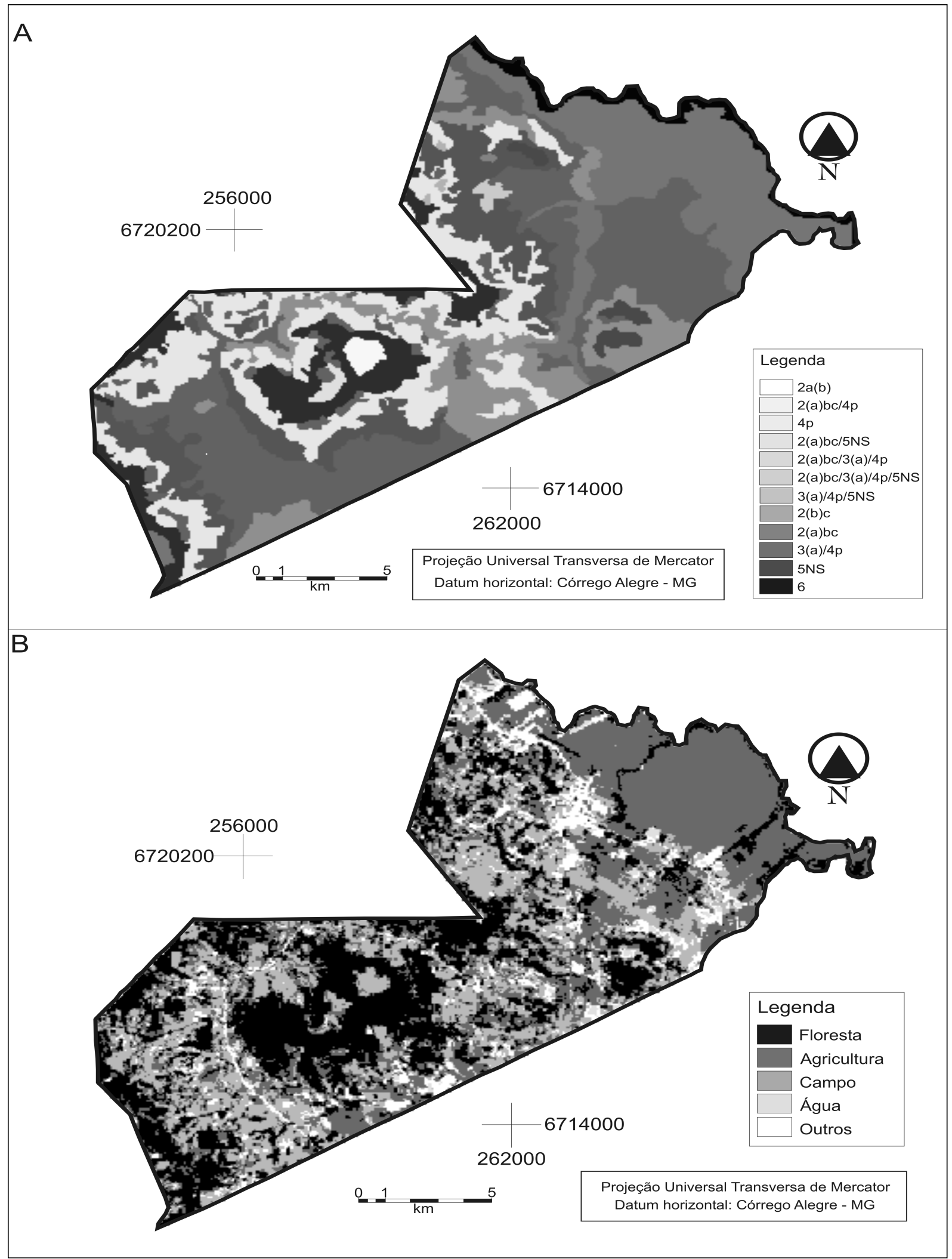

Figura 2 - Mapa de aptidão agrícola das terras (A) e mapa de uso atual das terras (B) do município de São João do Polêsine.

Ciência Rural, v.36, n.1, jan-fev, 2006. 


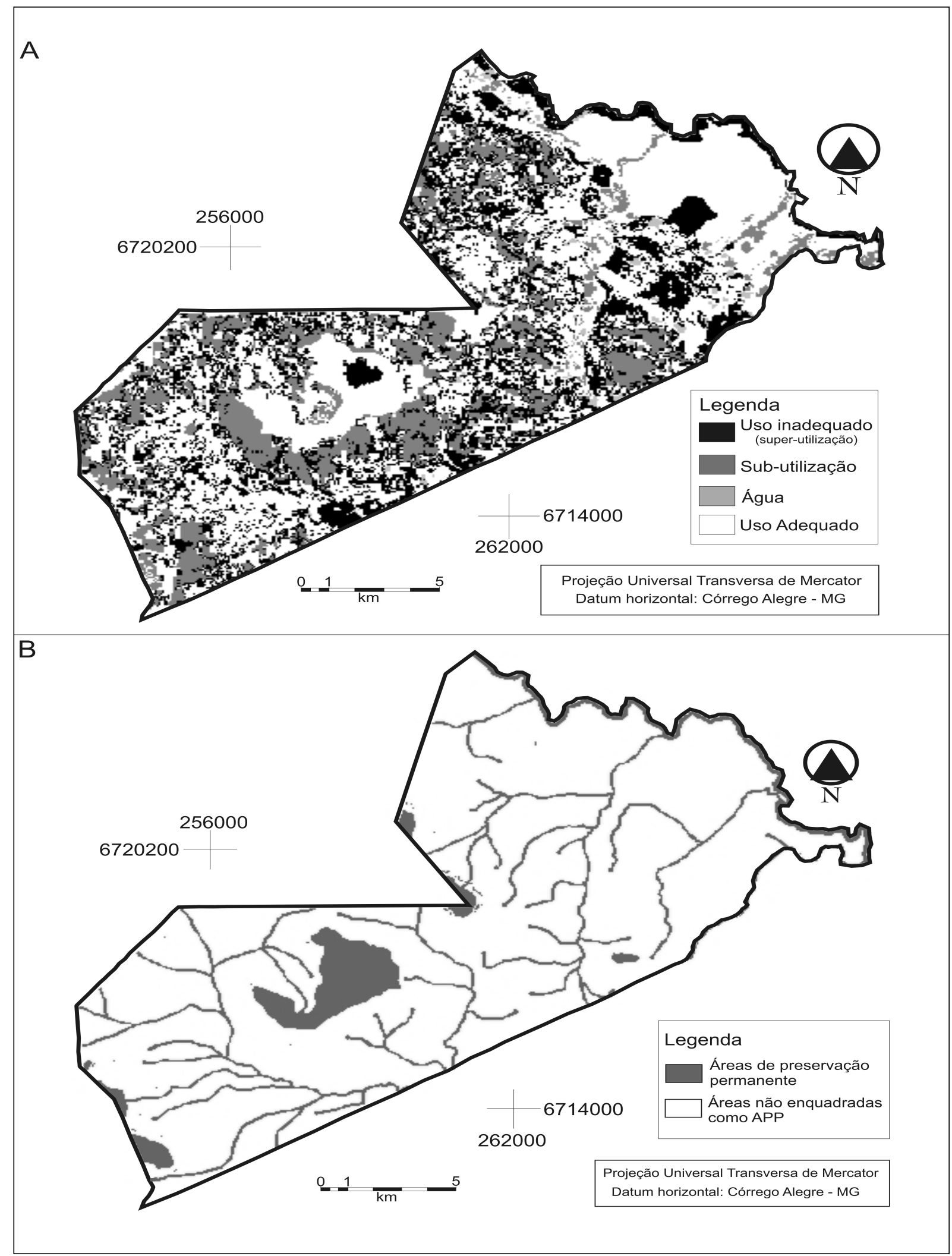

Figura 3 - Mapa de conflitos de uso das terras (A) e mapa de áreas de preservação permanente (B) do município de São João do Polêsine. 
e aplicação de produtos químicos, os quais, segundo MACHADO et al. (2003) e RHEINHEIMER et al. (2003), podem provocar contaminação dos recursos hídricos dentro e fora das áreas de produção.

\section{CONCLUSÕES}

Neste trabalho, foi possível identificar e mapear, através da determinação dos conflitos de uso das terras, que o município apresenta $51,5 \%$ da área com uso conforme sua aptidão, $18,7 \%$ subutilizado e $27,9 \%$ com inadequação de uso. No entanto, esta avaliação não engloba a legislação ambiental, na qual se verifica que $14,8 \%$ da área enquadra-se como APP, sendo que $8,6 \%$ desta apresenta conflitos de uso devido à sua utilização com lavouras e pastagens. Da mesma forma, 90,8\% da área enquadrada como APP apresenta algum tipo de aptidão agrícola, entretanto, tem seu uso limitado pela legislação ambiental. A principal fonte de degradação dos recursos naturais no município de SJP é a atividade agropecuária.

O planejamento dos recursos naturais de um município necessita da elaboração de mapas de aptidão de uso, uso atual e de áreas de preservação permanente, que, por cruzamentos e sobreposição, permitam determinar as áreas com conflitos de uso. Com estas informações, é possível planejar o uso das terras para obtenção de rendimentos economicamente e ambientalmente sustentáveis.

\section{REFERÊNCIAS}

AZEVEDO, A.C. de; DALMOLIN, R.S.D. Solos e ambiente: uma introdução. Santa Maria: Pallotti, 2004. 100p.

BRASIL. Lei Federal $n^{\circ}$ 4.771, de 15 de setembro de 1965 - Código florestal. 1965. Capturado em 17 set. 2004. Online. Disponível na internet: http://www.mma.gov.br/conama/

BURIOL, G.A. et al. Cartas mensais e anuais das temperaturas médias, das médias das temperaturas máximas e das médias das temperaturas mínimas do estado do Rio Grande do Sul. Revista do Centro de Ciências Rurais, Santa Maria, v.9, p. 1-53, 1979. (Suplemento).

CAMARA, G. et al. SPRING: Integrating remote sensing and GIS by object-oriented data modelling. Computers \& Graphics, v.20, n.3, p.395-403, 1996.
CONAMA - Conselho Nacional do Meio Ambiente. Resolução $\mathbf{N}^{0}$ 303, de 20 de março de 2002 - Dispõe sobre parâmetros, definições e limites de áreas de preservação permanente. Capturado em 15 set 2004. Online. Disponível na internet: http://www.mma.gov.br/conama/

DALMOLIN, R.S.D. et al. Relação entre as características e utilização de levantamentos de solos de diferentes escalas. Ciência Rural, Santa Maria, v.34, n.5, p.1479-1486, 2004.

DENT, D.; YOUNG, A. Soil survey and land evaluation. London: E \& FN Spon, 1993. 292p.

EMBRAPA. Sistema Brasileiro de Classificação de Solo. Brasília: EMBRAPA, 1999. 412p.

FORMAGGIO, A.R. et al. Sistemas de Informações Geográficas na obtenção de aptidão agrícola e de taxa de adequação de uso das terras. Revista Brasileira de Ciência do Solo, Campinas, v.16, p.249-256, 1992.

KLAMT, E. et al. Solos do Município de São João do Polêsine: classificação, distribuição geográfica e aptidão de uso. Santa Maria: CCR, Departamento de Solos, 1997. $93 \mathrm{p}$.

LEPSCH, I.F. et al. Manual para levantamento utilitário do meio físico e classificação de terras no sistema de capacidade de uso. Campinas: SBCS, 1991. 175p.

MACHADO, S.L. de O. et al. Lavoura arrozeira e recursos hídricos. Ciência \& Ambiente, Santa Maria, v.27, p.97$106,2003$.

PIROLI, E.L. et al. Análise do uso da terra na microbacia do arroio do Meio - Santa Maria - RS, por sistema de informações geográficas e imagens de satélite. Ciência Rural, Santa Maria, v.32, n.3, p.407-413, 2002.

RAMALHO FILHO, A.; BEEK, K.J. Sistema de avaliação da aptidão agrícola das terras. 3.ed. rev. Rio de Janeiro: EMBRAPA - CNPS, 1995. 65p.

RHEINHEIMER, D. dos S. et al. Impactos das atividades agropecuárias na qualidade da água. Ciência \& Ambiente, Santa Maria, v.27, p.85-96, 2003.

RODRIGUES, J.B.T. et al. Utilização de sistemas de informação geográfica na avaliação do uso da terra em Botucatu (SP). Revista Brasileira de Ciência do Solo, Campinas, v.25, p.675-681, 2001.

STRECK, E.V. et al. Solos do Rio Grande do Sul. Porto Alegre: Emater/RS - UFRGS, 2002. 116p. 